\title{
Effect of Pharmacists' Interventions on the Appropriateness of Empiric Vancomycin Therapy in Oncology Patients with Febrile Neutropenia
}

\author{
Nour Baghdady 1,2 , PharmD, BCPS, MPH, Daniel Voit ${ }^{2}$, PharmD, \\ Anne M. McDonnell ${ }^{2}$, PharmD, MBA, BCOP, CPPS, David W. Kubiak², PharmD, BCPS \\ 'Clinical Pharmacy Department, Faculty of Pharmacy, King Abdulaziz University, Jeddah, Saudi Arabia" \\ ${ }^{2}$ Department of Pharmacy, Brigham and Women's Hospital, Boston, Massachusetts, U.S.A.
}

\author{
Correspondence \\ Dr. Nour Baghdady \\ 163 Middlesex Ave., Unit 2 \\ Medford, MA 02155 \\ U.S.A. \\ e-M: nbaghdady@gmail.com \\ Submission: 10 Nov. 2019 \\ Accepted: 19 Nov. 2019
}

\section{Citation}

Baghdady N, Voit D, McDonnell AM, Kubiak DW. Effect of pharmacists' interventions on the appropriateness of empiric vancomycin therapy in oncology patients with febrile neutropenia. JKAU Med Sci 2019; 26 (2): 53-59. DOI: 10.4197/ Med.26-2.6

Copyright: (๑The Author(s), YEAR. Publisher. The Journal of King Abdualziz University - Medical Sciences is an Official Publication of "King Abdulaziz University". It is an open-access article distributed under the terms of the Creative Commons Attribution Non-Commercial License, which permit unrestricted non-commercial use, distribution, and reproduction in any medium, provided the original work is properly cited.

\begin{abstract}
The purpose of this observational study is to evaluate the effect of an active pharmacy intervention to facilitate timely discontinuation of empiric vancomycin therapy in oncology patients with febrile neutropenia who lack objective evidence of a Gram-positive infection. This was a two-phase study. Vancomycin use was evaluated retrospectively on all oncology patients with febrile neutropenia over four weeks (phase I). In a parallel four weeks a year later, vancomycin use in this patient population was evaluated prospectively (phase II). In the absence of evidence of Gram-positive infection after 72 hours of treatment initiation, the team was contacted by a pharmacist to encourage discontinuation. Usage was compared between both phases. Forty-three patients in phase I and 25 patients in phase II were treated with vancomycin with no evidence for Gram-positive infections. Pharmacists' interventions were documented on 18 patients in phase II. Of these, $56 \%$ of interventions to discontinue vancomycin were accepted, but only $33.3 \%$ of patients had treatment stopped within 72 hours of initiation. Although not significant, a trend in more appropriate use of vancomycin in oncology patients with febrile neutropenia was observed. Pharmacist's interventions might have played a role in this observation.
\end{abstract}

\section{Keywords}

Vancomycin; De-escalation; Febrile neutropenia

\section{Introduction}

$N$ eutropenia is a complication of chemotherapy which can predisposecancer patients to infections and cause significant morbidity and mortality ${ }^{[1]}$. The magnitude and duration of neutropenia puts patients at a higher risk of developing infections ${ }^{[1]}$. Often times, fever is the only sign of infection due to impaired cellmediated immunity and inflammatory responses in these patients ${ }^{[1]}$. Febrile neutropenia (FN) is a medical emergency in oncology patients, early recognition and initiation of empiric broad spectrum antimicrobials is of critical importance $\mathrm{e}^{[1,2]}$. Clinical practice guidelines by the National Comprehensive Cancer Network 
(NCCN) and the Infectious Disease Society of America (IDSA) recommend empiric treatment with broad spectrum antimicrobials with antipseudomonal beta lactams, e.g., an antipseudomonal beta lactam or a carbepenam typically as monotherapy ${ }^{[1,3]}$. Treatment with glycopeptide antibiotics such as vancomycin, on the other hand, should be reserved for patients with cultures growing Gram-positive pathogens or indications suggesting likelihood of a Gram-positive infectious process (GPI) such as: hemodynamic instability, skin and soft tissue infection, infections suspected to be related to catheter, or pneumonia ${ }^{[1]}$. Current data show that empiric treatment with vancomycin without evidence of a GPI did not improve outcomes in $\mathrm{FN}^{[3,4]}$. On the contrary, it put patients at risk of unnecessary side effects and increased the likelihood of promoting resistance in pathogens such as Enterococcus spp. and Staphylococcus spp. ${ }^{[1]}$.

Over the past few years, the use of vancomycin has been increasing significantly, particularly in patients with $\mathrm{FN}^{[2]}$. Recent data shows that vancomycin initiation for FN increased from $17.2 \%$ in 2000 to $54.9 \%$ in $2010^{[2]}$. We observed this increase at our 793-bed tertiary care academic medical center, the Brigham and Women's Hospital, in the form of a steady increase in defined daily doses (DDD) of vancomycin per 100 patient days admitted to oncology and hematopoietic stem cell transplant (HSCT) wards and in general hospital wards as shown in Figure 1. A guideline for antimicrobial use in patients with $\mathrm{FN}$ was created based on published national guidelines and implemented at our institution in 2007. This guideline specifies that vancomycin should only be used in patients with an indication suggesting the likelihood of GPI. It also recommends the discontinuation of vancomycin if cultures remain

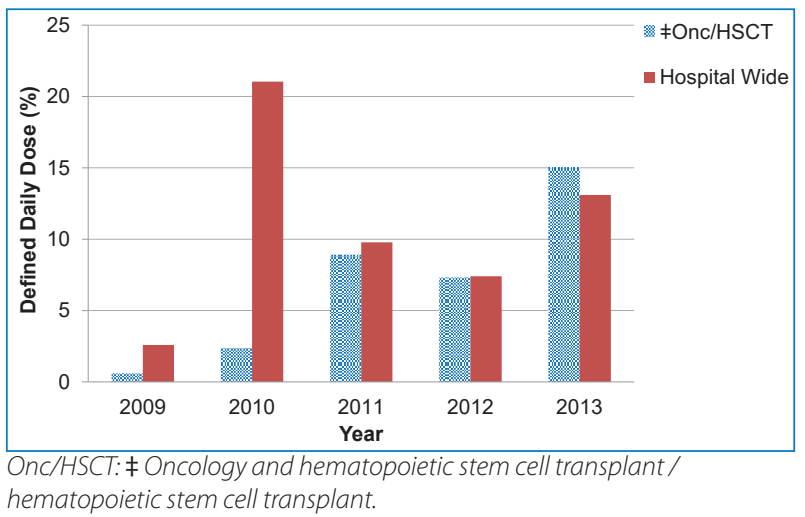

Figure 1. Defined daily doses of vancomycin per 100 patient days in oncology and hematopoietic stem cell transplant wards and hospital wide in the month of January by year. negative after 48- to 72-hours of therapy. At our institution, promoting adherence to treatment guidelines, including FN guidelines, and antimicrobial stewardship is one of the clinical pharmacists' daily duties. This has been established based on the evidence proving the benefits pharmacists can provide in discontinuation of unnecessary antibiotics, reduction in overall exposure to antimicrobials and decreased infection-related length of stay ${ }^{[5]}$.

We conducted a pilot observational study to evaluate the impact of pharmacists' interventions on the discontinuation of empiric vancomycin therapy in oncology patients with FN lacking evidence of GPI within 72 hours of drug initiation.

\section{Materials and Methods}

This observational study was conducted over two phases. The first phase (phase I) is the pre-intervention phase. Data was collected retrospectively over a period of four weeks starting January 1, 2012 through February 1, 2012 and was used as baseline data to identify the current practice at our institution. Data from this phase was used as a comparative arm for the intervention phase. In the second phase (phase II), the intervention phase, data was collected prospectively over four weeks starting January 1, 2013 through February 1, 2013, one year later.

During both phases, all oncology patients with FN on receiving systemic vancomycin were evaluated. Inclusion criteria included patients with neutropenia and fever admitted to our oncology and HSCT wards. Fever was defined as a body temperature of more than 38 degrees Celsius. Neutropenia was defined as an absolute neutrophil count (ANC) of less than or equal to $0.5 \times 10^{3}$ cells per $\mathrm{mm}^{3}$. Patients with an ANC between 0.5 to $1.5 \times 103$ cells per mm3 with an anticipated decline to less than $0.5 \times 103$ cells per mm3 within 48 hours were also evaluated to capture patients trending into neutropenia. Reasons for exclusion were ages less than 18 years or treatment with vancomycin for an indication approved by our institution's guidelines including cultures growing Gram-positive bacteria, hemodynamic instability, skin and soft tissue infection, infections suspected to be related to catheter, or pneumonia.

During the intervention phase (Phase II), patients with FN admitted to an oncology service and started on vancomycin therapy were monitored for the 
confirmation of an indication within the following 48 hours. If patients were found not to have an indication approved by our guideline, the responding clinician was paged to discuss the indication of vancomycin therapy and to consider discontinuation. An intervention was considered accepted if treatment was discontinued before the next day. If treatment continued and the pharmacist did not receive a call back from the covering team, another page was sent as a reminder. No more than two pages were sent per case. Interventions were considered not accepted if therapy continued beyond 72 hours. Vancomycin use in concordance with our guidelines, i.e., where an indication was present or if deescalated within 72 hours, was defined as "appropriate". Otherwise, use was deemed "inappropriate".

The number of pharmacist-led clinically appropriate vancomycin discontinuations within 72 hours was assessed. In addition, we evaluated the overall vancomycin days on therapy (DOT) and the combined number of appropriate versus inappropriate therapy.

The sample size in this study is small and, therefore, assumed to be not normally distributed; medians and interquartile ranges were used for descriptive statistics and Wilcoxon signed-rank test were used to compare differences in medians. We used chi-squared for categorical data and all $p$ values were two-tailed and were significant if $<0.05$.

This observational study was approved by the Partners Human Research Committee (PHRC), the
Institutional Review Board of Partners HealthCare, for adherence to ethical, federal and institutional guidelines. As this was an observational study of pharmacists' standard practice, a waiver of informed consent was approved by the PHRC.

\section{Results}

In total, 119 patients were evaluated; 65 in phase I and 54 in phase II. Fifty-one cases, 22 in phase I and 29 in phase II, were excluded because vancomycin was used for indications consistent with our guidelines (Fig. 2). Baseline characteristics and allergy profiles were similar in both phases (Table 1A and 1B).

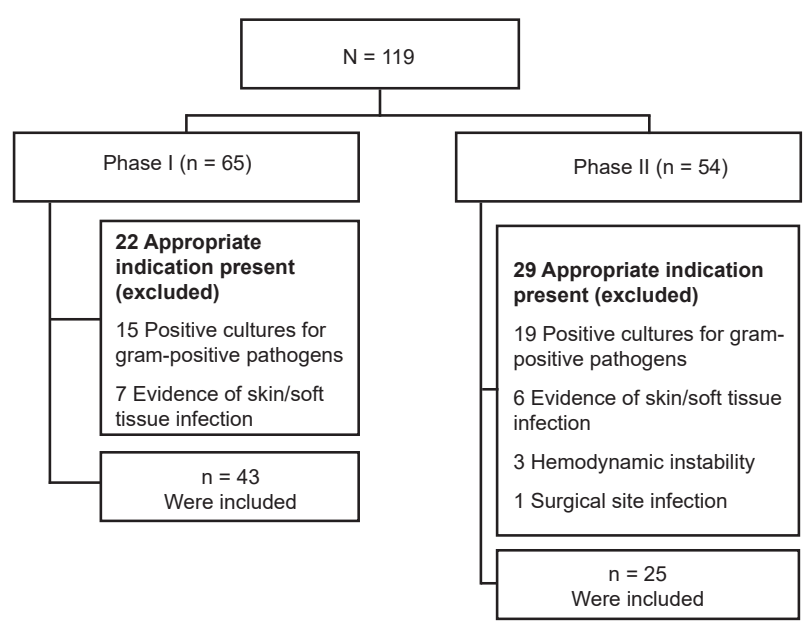

Figure 2. Study enrollment.

Table 1a. Baseline characteristics (Medians [Interquartile Range])

\begin{tabular}{|l|c|c|c|}
\hline \multicolumn{1}{|c|}{ Baseline } & $\begin{array}{c}\text { Phase I } \\
(\mathbf{n = 4 3 )}\end{array}$ & $\begin{array}{c}\text { Phase II } \\
(\mathbf{n}=\mathbf{2 2})\end{array}$ & P value \\
\hline Age (years) & $55[20.5]$ & $62[20.25]$ & 0.12 \\
\hline Male sex (\%) & $21(48.84 \%)$ & $10(45.5 \%)$ & 0.8 \\
\hline Weight $(\mathrm{Kg})$ & $67.3[28.05]$ & $78.5[20.13]$ & 0.1 \\
\hline ANC $\left(\mathrm{x} 10^{3} \mathrm{cell} / \mathrm{s} / \mathrm{mm}^{3}\right)$ & $0.44[0.94]$ & $0.12[0.62]$ & 0.23 \\
\hline WBC $\left(\mathrm{x} 10^{3} \mathrm{cell} / \mathrm{s} / \mathrm{\mu m}^{3}\right)$ & $0.8[1.3]$ & $0.91[1.97]$ & 0.76 \\
\hline Serum $($ reatinine $(\mathrm{mg} / \mathrm{dL})$ & $0.69[0.49]$ & $0.73[0.46]$ & 0.6 \\
\hline
\end{tabular}

Table $1 \mathrm{~b}$. Allergies to antibiotics (Some patients had more than one allergy so number)

\begin{tabular}{|l|c|c|c|}
\hline \multicolumn{1}{|c|}{ Medication } & Phase I & Phase II & P values \\
\hline Any allergy & $51.16 \%$ & $45.45 \%$ & 0.66 \\
\hline Penicillin & $18.60 \%$ & $13.04 \%$ & 0.61 \\
\hline Cephalosporins & $16.28 \%$ & $8.70 \%$ & 0.43 \\
\hline Quinolones & $6.98 \%$ & $1.90 \%$ & 0.7 \\
\hline Tetracyclines & $4.65 \%$ & $0.00 \%$ & 0.3 \\
\hline
\end{tabular}


Figure 3. Interventions in phase II.

Table 2. Overall appropriate therapy

\begin{tabular}{|l|c|}
\hline & Phase I $(\mathbf{n}=\mathbf{6 5})$ \\
\hline Appropriate & $45(69.3 \%)$ \\
\hline Non-appropriate & $20(30.7 \%)$ \\
\hline & Phase II ( $\mathbf{n}=\mathbf{5 4})$ \\
\hline Appropriate & $45(83.3 \%)$ \\
\hline Non-appropriate & $9(16.7 \%)$ \\
\hline
\end{tabular}

In phase II, interventions occurred on 18 patients (Fig. 3) of which 10 (56\%) were accepted; 6 (33\%) were successfully implemented within the 72-hour window. Interventions were not accepted on 8 patients: in 3 cases, an indication was present but not documented in the patient's medical record at the point of intervention. Documentation occurred later on at which point it was considered an appropriate indication and excluded from our statistics. The team decided to continue therapy despite recommendation to discontinue in 5 patients. This leads to a total of 13 (7 spontaneously and 6 upon pharmacist's recommendation) discontinuations within 72 hours in phase II (13/22; 59.1\%) compared to $23(23 / 43 ; 53.5 \%)$ in phase I with no statistical significance $(p=0.86)$.

The median vancomycin DOT was not significantly different between phases I and II (3 [IQR $=3.25]$ days vs. $3[\mathrm{IQR}=2]$ days; $\mathrm{p}=0.81$ ). The median length of hospitalization was also similar between both groups (17 [30.5] vs. 8 [9] days; $\mathrm{p}=0.08$ ).
8 interventions

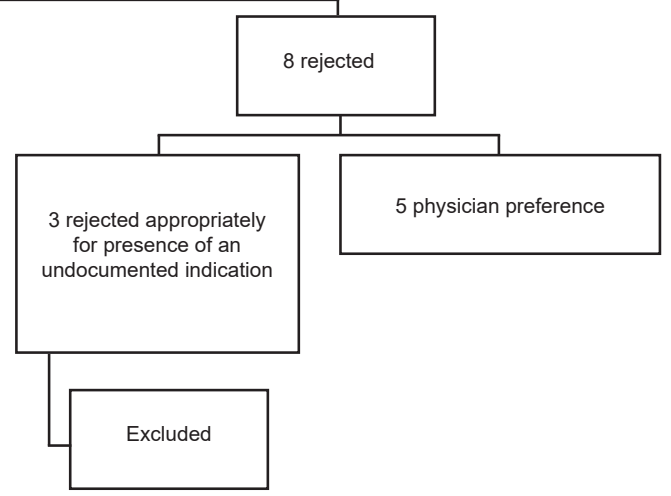

Of the total $119 \mathrm{FN}$ patients receiving vancomycin therapy, use was appropriate in $45(69.3 \%)$ of 65 patients during phase I and $45(83.3 \%)$ of 54 patients during phase II (Table 2; $p=0.07$ ).

\section{Discussion}

Although vancomycin is an effective antibiotic, its use in patients with FN should be reserved for those with appropriate indications to decrease the risk of adverse events and the risk of adverse events and resistance ${ }^{[1]}$. In our study, we did not see significant results between both phases; however, we observed a slight non-significant towards more appropriate use of vancomycin in accordance with our institutional guidelines in phase II. This appropriateness was demonstrated through initiation of vancomycin in patients with approved indications ( 22 in phase I vs. 29 in phase II; Figure 2) and discontinuation within 72 hours of absence of indications (23 [53.5\%] in phase I vs. 13 [59.1\%] in phase II). Pharmacists' vigilance and active interventions might be a contributing factor to this improvement.

Our study has some limitations. First, this study is a pilot study that evaluated a small sample over a short period of time. The number of patients captured was lower than expected, which contributed heavily to the lack statistical significance. Second, phase I and phase II are separated by one year. The reason this was conducted was to prevent the introduction of potential confounding factors with the month 
selection such as influenza virus and norovirus activity increase in the winter months, which my lead to an increase in hospital admissions and lengths of stay ${ }^{[6,7]}$. However, this one-year period potentially introduces confounders, including changes in hospital personnel, changes in levels of education, and increased attention to antimicrobial stewardship. Third, our method of intervention of paging the covering clinician, rather than a face-to-face conversation with the team at the time of ordering, may have contributed to unsuccessful interventions and lack of team responsiveness. Collective decision making during rounds has been proven to be effective ${ }^{[8,9]}$. Another obstacle was interventions on weekends, particularly evening shifts. Physicians, who were likely night-floats, residents, or interns, were hesitant to make changes to a patient's regimen without consent from the primary team. This led to delays beyond the 72-hour window in these situations. Finally, in the intervention phase (phase II) there was the advantage of having a conversation with the covering team and identifying undocumented indications that then deemed treatment appropriate. This introduces bias and may have led to an underestimation of appropriate therapy in phase I. Although our study sample was not large enough to show a statistically significant difference in the benefit measured, there was an improvement in prescribing and de-escalation of vancomycin in neutropenic patients. This aligns with the growing body of evidence that demonstrates pharmacists are integral to antibiotic stewardship ${ }^{[10]}$. Current guidelines emphasize the need of pharmacists' involvement in antimicrobial stewardship in all patient populations including those that are immunocompromised ${ }^{[10,11]}$. In this study, two main methods of antibiotic stewardship were exercised: development and implementation of facility specific treatment recommendations and prospective audit and feedback on specific antibiotics. Both methods are described as stewardship methods in inpatients in the Center of Disease Prevention and Control Core Elements of Hospital Antibiotic Stewardship Programs document ${ }^{[12]}$.

Moving forward, a larger prospective trial is needed to evaluate the benefit gained from implementing a pharmacist-run stewardship program in this patient population. In such a study, cost-savings would be a useful parameter to evaluate. Overcoming obstacles will require raising awareness to this issue and intensive education of all members of the health care team (including physicians, nurses, and pharmacists). This teaching opportunity is also an area where pharmacists can play an active and effective role.

\section{Conclusion}

Prolonged vancomycin use in oncology patients with febrile neutropenia with no evidence of a grampositive infection is unnecessary. Discontinuation after 72 hours is strongly encouraged. Clinical pharmacists are an integral component of effective antimicrobial stewardship programs.

\section{Conflict of Interest}

Nour Baghdady, Daniel Voit, Anne M. McDonnell, David W. Kubiak work at the Brigham and Women's Hospital. No sponsorship or funding was received by any of the authors in relation to this paper. No editorial or medical writing assistance was received in preparing this manuscript. Authors have no other relevant conflicts of interest to disclose.

\section{Disclosure and Ethical Approval}

This observational study was approved by the PHRC, the Institutional Review Board of Partners HealthCare, for adherence to ethical, federal and institutional guidelines. As this was an observational study of pharmacists' standard practice, a waiver of informed consent was approved by the PHRC.

\section{References}

[1] Freifeld AG, Bow EJ, Sepkowitz KA, Boeckh MJ, Ito JI, Mullen CA, Raad II, Rolston KV, Young JA, Wingard JR; Infectious Diseases Society of America. Clinical practice guideline for the use of antimicrobial agents in neutropenic patients with cancer: 2010 Update by the Infectious Diseases Society of America. Clin Infect Dis 2001; 52(4): e56-93.

[2] Wright JD, Neugut Al, Ananth CV, Lewin SN, Wilde ET, LuYS, Herzog TJ, Hershman DL. Deviations from guideline-based therapy for febrile neutropenia in cancer patients and their effect on outcomes. JAMA Intern Med 2013; 173(7): 559568.

[3] Baden LR, Swaminathan S, Angarone M, Blouin G, Camins BC, Casper C, Cooper B, Dubberke ER, Engemann AM, Freifeld AG, Greene JN, Ito JI, Kaul DR, Lustberg ME, Montoya JG, Rolston K, Satyanarayana G, Segal B, Seo SK, Shoham S, Taplitz R, Topal J, Wilson JW, Hoffmann KG, Smith C. Prevention and treatment of Cancer-related infections, Version 2.2016, NCCN Clinical Practice Guidelines in Oncology. J Natl Compr Canc Netw 2016: 14(7): 882-913. 
[4] Paul M, Borok S, Fraser A, Vidal L, Cohen M, Leibovici L. Additional anti-Gram-positive antibiotic treatment for febrile neutropenic cancer patients. Cochrane Database Syst Rev 2005: 20 (3): CD003914.

[5] Wong JR, Bauer KA, Mangino JE, Goff DA. Antimicrobial stewardship pharmacist interventions for coagulasenegative staphylococci positive blood cultures using rapid polymerase chain reaction. Ann Pharmacother 2012: 46(11): 1484-1490.

[6] [No authors listed]. Burden of Norovirus IIIness in the U.S. Centers for Disease Control and Prevention. <https://www. cdc.gov/norovirus/trends-outbreaks/burden-US.html>.

[7] [No authors listed]. Influenza (Flu). Flu season. 2018 <https://www.cdc.gov/flu/about/season/flu-season.htm>.

[8] Kaboli PJ, Hoth AB, McClimon BJ, Schnipper JL. Clinical pharmacists and inpatient medical care: a systematic review. Arch Intern Med 2006: 166(9): 955-964.

[9] Leape LL, Cullen DJ, Clapp MD, Burdick E, Demonaco HJ, Erickson Jl, Bates DW. Pharmacist participation on physician rounds and adverse drug events in the intensive care unit. JAMA 1999: 282(3); 267-270..

[10] Barlam TF, Cosgrove SE, Abbo LM, MacDougall C, Schuetz AN, Septimus EJ, Srinivasan A, Dellit TH, Falck-Ytter YT, Fishman NO, Hamilton CW, Jenkins TC, Lipsett PA, Malani PN, May LS, Moran GJ, Neuhauser MM, Newland JG, Ohl CA, Samore MH, Seo SK, Trivedi KK. Executive Summary: Implementing an Antibiotic Stewardship Program: Guidelines by the Infectious Diseases Society of America and the Society For Healthcare Epidemiology of America. Clin Infect Dis 2016: 62(10): 1197-1202.

[11] Aitken SL, Nagel JL, Abbo L, Alegria W, Barreto JN, Dadwal S, Freifeld AG, Jain R, Pergam SA, Tverdek FP, Seo SK; Antimicrobial Stewardship in Cancer Consortium ASCC. Antimicrobial Stewardship in Cancer Patients: The Time is Now. J Natl Compr Canc Netw 2019; 17 (7): 772-775.

[12] Pollack LA, Srinivasan A. Core elements of hospital antibiotic stewardship programs from the Centers for Disease Control and Prevention. Clin Infect Dis 59 Suppl 3: S97-100. 


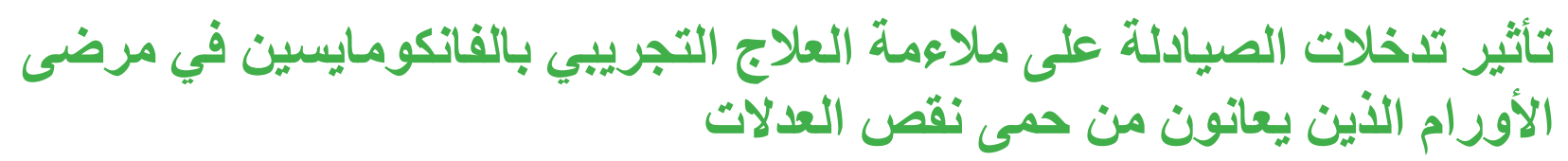

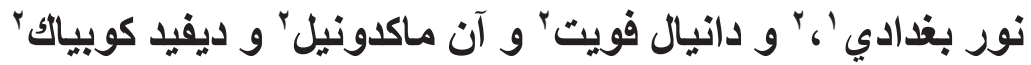

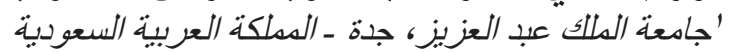

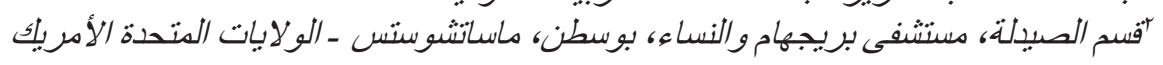

المستخلص. الهذف: الهدف من هذه الدراسة هو تقبيم نأثير التنخل الصبدلي الفعال للمساعدة في إيقاف العلاج المبدئي

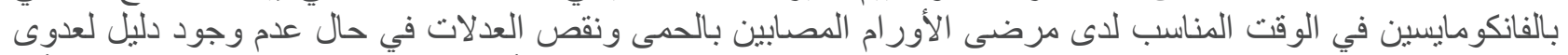

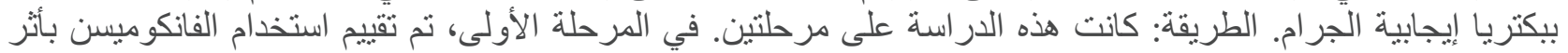

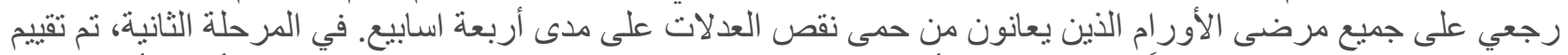

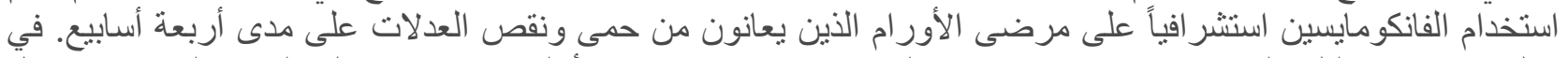

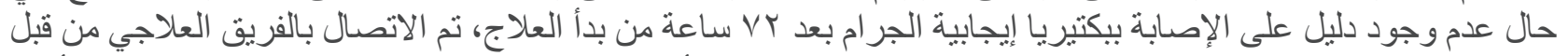

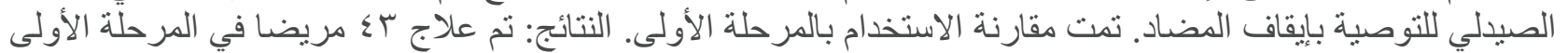

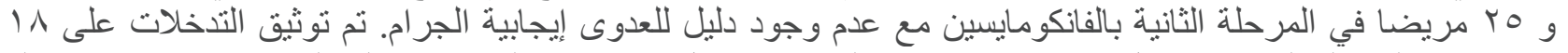

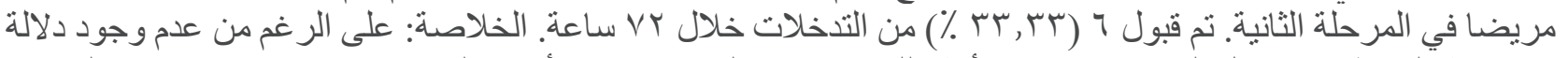

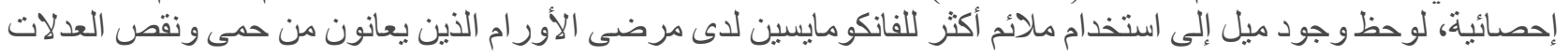
في المرحلة الثانية و عليه فقد يكون لتدخلات الصيدلي دور في هذه الملاحظة. 